\title{
A Península e a Ilha \\ Ibéricos e ingleses no Atlântico dos séculos XVI ao XIX
}

\section{The Peninsula and the Island}

Iberian and English in the Atlantic from the 16th to the 19th Centuries

Luis Guilherme KALIL ${ }^{1}$ http://orcid.org/0000-0002-4332-6735

${ }^{1}$ Departamento de História

Universidade Federal Rural do Rio de Janeiro

Av. Governador Roberto Silveira, s/n, Nova Iguaçu, RJ, 26.020-740, Brasil

lgkalil@yahoo.com.br

Obra resenhada

CAÑIZARES-ESGUERRA, Jorge (ed.). Entangled Empires: the AngloIberian Atlantic, 1500-1830. Philadelphia: University of Pennsylvania Press, 2018. 331p.

Em sua investigação sobre os primeiros exploradores europeus do território norte-americano, Tony Horwitz (2010, p.16) afirma haver um "século perdido", que iria de 1492 até 1620, com o desembarque do Mayflower. O vazio apontado pelo jornalista é ilustrado através da entrevista com um guarda-florestal de Plymouth, frequentemente questionado por turistas se este rochedo seria o local onde Colombo teria desembarcado no Novo Mundo.

Esta curiosa confusão de datas e personagens se relaciona com questões mais amplas acerca do passado colonial americano e dos impérios construídos por ingleses e ibéricos durante a Modernidade. A visão de uma experiência inglesa na América como algo único e isolado do

Recebido: 11 out. 2018 | Revisto pelo autor: 22 out.2018 | Aceito: 30 out. 2018 http://dx.doi.org/10.1590/0104-87752019000100014

Varia Historia, Belo Horizonte, vol. 35, n. 67, p. 383-387, jan/abr 2019 
restante do continente possui uma longa e variada trajetória marcada por aspectos como as rivalidades imperiais e os embates entre católicos e protestantes no período. Esse processo ganha força nos Estados Unidos independente através dos esforços de construção de um passado nacional que encontra nos puritanos ingleses o ponto de partida para $\mathrm{o}$ Destino Manifesto da nação. Já no século XX, essa perspectiva fomenta uma abordagem - há muito criticada pelos historiadores, mas ainda atraente em sua tipologia simplista, dicotômica e determinista - que identifica na América a existência de dois modelos opostos de colonização: exploração ou povoamento.

Ao longo de sua carreira, Jorge Cañizares-Esguerra vem dedicando grandes esforços na tentativa de negar o isolamento e historicizar a construção deste antagonismo que silencia as conexões, enfatizando que a trajetória do Império inglês - e, mais amplamente, da própria Modernidade - só seria compreensível se a experiência ibérica fosse colocada em primeiro plano. Nesse sentido, o autor enfatizou em obras anteriores o papel central do Império espanhol e de suas colônias americanas em alguns dos principais debates epistemológicos do século XVIII (2001), os vários pontos em comum entre conquistadores hispânicos e religiosos puritanos (2006) e a "dramática influência" das ideias, políticas e ações ibéricas nas colônias ultramarinas inglesas, marcadas pela inveja em relação à Espanha (Cañizares-Esguerra; Dixon, 2017). Em todos os casos, há um questionamento direto em relação aos recortes nacionais e imperiais e também às perspectivas tradicionais de Modernidade e de História Atlântica, que deixariam de lado a complexidade e a riqueza das trajetórias de pessoas, bens, ideias e escritos. Como alternativa, o historiador, em conjunto com outros pesquisadores (Gould, 2007), propõe a perspectiva de "Impérios Emaranhados" (2012), cujas trajetórias seriam impossíveis de serem compreendidas separadamente.

O presente livro é mais uma contribuição nessa direção. Resultado de um encontro organizado por Cañizares-Esguerra e seus orientandos na Universidade do Texas, em 2014, Entangled Empires visa, através de seus doze artigos, reforçar as críticas às abordagens nacionais ou imperiais através da análise de uma ampla gama de temas, documentos, 
personagens e regiões que se estendem do século XVI ao início do XIX. A ideia de um esforço conjunto ${ }^{1}$ em defesa da perspectiva de Impérios Emaranhados fica visível através não apenas de referências conceituais e bibliográficas comuns, mas também pelas recorrentes menções nos artigos a outros textos do mesmo livro, o que reforça o diálogo entre eles e a unidade da obra, permitindo conexões que escapam aos temas específicos de cada um dos autores.

Como exemplo, podemos citar os estudos de Mark Sheaves (Cap. 1) e de Christopher Heaney (Cap. 4), que destacam a fragilidade das identificações nacionais em relação a determinadas fontes históricas e personagens. No primeiro caso, o autor persegue a trajetória de ingleses como um comerciante e escritor que viveu em terras espanholas denominado nos documentos do período tanto como Pedro Sánchez quanto como Henry Hawks, a depender de seu local de publicação. Já Heaney analisa a tradução e adaptação para o inglês feita por Richard Eden de trechos das Décadas de Pedro Mártir de Anglería, identificando a influência da Utopia de Thomas More (que, por sua vez, foi influenciado pelas cartas de Américo Vespúcio) e a tentativa de, através dos escritos, inspirar os ingleses em direção ao Novo Mundo.

Outros capítulos ressaltam a atuação de grupos que transitavam entre a península, a ilha e o mundo atlântico. É o caso do artigo de Michael Guasco (Cap. 2), para quem os primeiros contatos dos ingleses com os africanos teriam sido pautados pela experiência ibérica anterior, da análise de Holly Snider (Cap. 5) a respeito dos judeus sefaraditas e de Christopher Schmidt-Nowara (Cap. 6) sobre a importância de alguns irlandeses para a expansão inglesa e suas múltiplas relações com os domínios ibéricos. Destacam-se ainda as contribuições de Bradley Dixon (Cap. 9), para quem a influência ibérica também foi fundamental para se compreender as expectativas e a atuação de determinados grupos indígenas em seus

1 É interessante observarmos que a produção de obras coletivas em torno de uma proposta de análise - algo ainda raro dentro da historiografia brasileira - é muito comum nos Estados Unidos. Apenas como exemplo, limitando-nos a livros que alcançaram grande repercussão dentro das pesquisas sobre o continente americano durante o período colonial, podemos citar obras como Negotiated Empires (2002) e Indian Conquistadors (2007). 
contatos com os ingleses, e de Kristie Flannery (Cap. 12), que altera o eixo de análise do Atlântico para o Pacífico, apontando a multiplicidade de relações existentes entre ingleses, espanhóis e nativos nas Filipinas durante a Guerra dos Sete Anos.

Em muitos capítulos, a referência aos impérios ibéricos presente no título da obra perde força para a abordagem mais específica das relações entre espanhóis e ingleses. Uma exceção é o trabalho de Benjamin Breen (Cap. 3), que destaca o papel central dos portugueses no comércio de "drogas" e na formação de redes comerciais e intelectuais. A decisão de concentrar a atenção no Atlântico anglo-ibérico traz ainda como consequência - algo reconhecido pelo próprio organizador em sua introdução (p. 3) - o pouco espaço dedicado a outros impérios, personagens e eventos fundamentais para a compreensão das questões que envolvem muitos dos artigos desta coletânea, como o caso da Revolução de Santo Domingo e, mais amplamente, da atuação francesa, holandesa, sueca, entre outras, no Novo Mundo, o que não só ampliaria a quantidade de impérios abordados, mas também aprofundaria o emaranhado entre eles.

Para além das possibilidades de ampliação do escopo de análise, que abrem espaço para outros esforços coletivos de pesquisa no futuro, Entangled Empires é uma importante contribuição no já longevo esforço de problematização do conceito de Império. Após percorrermos as trajetórias dos textos, produtos e personagens além dos debates intelectuais, negociações políticas e conflitos armados analisados pelos autores que participam desta coletânea, torna-se cada vez mais difícil identificarmos as especificidades e os limites há muito identificados entre os impérios construídos pelos ibéricos e ingleses.

\section{REFERÊNCIAS BIBLIOGRÁFICAS}

CANIIZARES-ESGUERRA, Jorge. How to Write the History of the New World: Histories, Epistemologies, and Identities in the Eighteenth-Century Atlantic World. Stanford: Stanford University Press, 2001.

CAÑIZARES-ESGUERRA, Jorge. Puritan Conquistadors: Iberianizing the Atlantic, 1550-1700. Stanford: Stanford University Press, 2006. 
CAÑIZARES-ESGUERRA, Jorge. Histórias emaranhadas: historiografias de fronteira em novas roupagens? In: FERNANDES, Luiz Estevam de Oliveira (org.). História da América: historiografia e interpretações. Ouro Preto: EDUFOP, 2012, p.14-39.

CAÑIZARES-ESGUERRA, Jorge; DIXON, Bradley J. "O lapso do rei Henrique VII”: inveja imperial e a formação da América Britânica. In: CAÑIZARES-ESGUERRA, Jorge; FERNANDES, Luiz Estevam de Oliveira; BOHN MARTINS, Maria Cristina (orgs.). As Américas na Primeira Modernidade. Curitiba: Prismas, 2017, p. 205-243.

DANIELS, Christine; KENNEDY, Michael V. Negotiated Empires: Centers and Peripheries in the Americas, 1500-1820. New York; London: Routledge, 2002.

GOULD, Eliga H. Entangled Histories, Entangled Worlds: The EnglishSpeaking Atlantic as a Spanish Periphery. American Historical Review, vol. 112, n. 3, p.764-786, 2007.

HORWITZ, Tony. Uma longa e estranha viagem: rotas dos exploradores norte-americanos. Rio de Janeiro: Rocco, 2010.

MATTHEW, Laura; OUDIJK, Michel. Indian Conquistadors: Indigenous Allies in the Conquest of Mesoamerica. Oklahoma: University of Oklahoma Press, 2007 